\title{
Chemical Properties of Water-Miscible Solvents Separated by Salting-out and Their Application to Solvent Extraction
}

\author{
Masaaki Tabata ${ }^{\dagger}$, Midori Kumamoto and Jun Nishimoto \\ Department of Chemistry, Faculty of Science and Engineering, Saga University, \\ Honjo-machi, Saga 840, Japan
}

\begin{abstract}
Fourteen water-miscible polar solvents were investigated for the separation from their aqueous solutions by salting-out using sodium chloride $\left(4 \mathrm{~mol} \mathrm{dm}^{-3}\right)$. The following solvents showed the phase separation: acetone, acetonitrile, 1,4dioxane, tetrahydrofuran, 1-propanol, and 2-propanol. The chemical properties of the separated organic solvents were determined by measuring $E_{\mathrm{r}}(30)\left(=1.196 \times 10^{5} / \lambda\left(\mathrm{kJ} \mathrm{mol}^{-1}\right)\right)$ and $D_{\mathrm{Il}, \mathrm{l}}\left(=1.196 \times 10^{5}\left(\lambda_{\mathrm{II}}{ }^{-1}-\lambda_{\mathrm{I}^{-1}}\right)\left(\mathrm{kJ} \mathrm{mol}^{-1}\right)\right)$ values from the spectral change of 2,6-diphenyl-4-(2,4,6-triphenylpyridinio)phenolate (DTP) and bis(1,3-propanediolato)vanadium(IV) ( $\left.\mathrm{VO}(\mathrm{acac})_{2}\right)$, where $\lambda, \lambda_{1}$, and $\lambda_{11}$ denote the absorption maximum wavelengths (nm) of DTP and VO(acac) $)_{2}$. Solvent properties of acetone, acetonitrile, 1,4-dioxane, and tetrahydrofuran were dramatically altered by the saltingout. Acceptability of the phase-separated solvents increased due to the dissolution of water molecules having large acceptor numbers. The ion-pair complex of tris(1,10-phenanthroline)iron(II) chloride was easily extracted into the phase-separated acetonitrile by the salting-out. Some metal chelates of 1-(2-pyridylazo)-2-naphthol (Hpan) and 8-quinolinol (Hox), 5,10,15,20-tetraphenylporphyrin $\left(\mathrm{H}_{2} \mathrm{tpp}\right)$, and ionic species $\left(\mathrm{H}_{2} \mathrm{Ox}^{+}\right.$, ox , and $\left.\mathrm{H}_{4} \mathrm{tpp}^{2+}\right)$ were also extracted into 1,4-dioxane. The raised donor and acceptor abilities of the phase-separated solvents allowed application to solvent extraction.
\end{abstract}

Keywords Salting-out, water-miscible solvents, $E_{\mathrm{T}}(30)$, solvent extraction

The salting-out technique has long been used for extraction of metal-chelates, ion-pairs, or organic materials, prior to atomic absorption spectrophotometry ${ }^{1}$, high-performance liquid chromatography ${ }^{2,3}$, polarography ${ }^{4}$, and absorption spectrophotometry. ${ }^{5}$ More recently, the salting-out using a surfactant of a watersoluble polymer has been used for preconcentration of porphyrins. ${ }^{6,7}$ Application of the salting-out to solvent extraction of ionic species will become easier when we understand the chemical properties of the phaseseparated solvents, because the solvents will have high polarity resulting from dissolution of water and electrolyte into the solvents by salting-out, in addition to water-miscible solvents themselves.

Several mechanisms have been proposed for the effects of electrolytes on the salting-out of water-miscible solvents. For example, some electrolytes have been classified as having either salting-out or salting-in effects and ranked according to their salting strength. Most of theories concerned with the salting-out effect have used salting-out coefficient (Setschenow constant) defined as $k_{\mathrm{s}}=1 / m\left(\log S_{0} / S\right)$, where $S_{0}$ and $S$ are the solubilities of the organic solvent in water and in an electrolyte solution of molality $m$, respectively..$^{8-10}$ However, microscopic properties like $E_{\mathrm{T}}(30)^{11}$ of the solvents phase-separated by the salting-out have not been studied.

In this paper we describe the chemical properties as donor and acceptor abilities of the phase-separated solvents by salting-out, i.e. $E_{\mathrm{T}}(30)\left(=1.196 \times 10^{5} / \lambda\right.$ $\left.\left(\mathrm{kJ} \mathrm{mol}^{-1}\right)\right)$ and $D_{\mathrm{II}, \mathrm{I}}\left(=1.196 \times 10^{5}\left(\lambda_{\mathrm{II}}^{-1}-\lambda_{\mathrm{I}}^{-1}\right)\left(\mathrm{kJ} \mathrm{mol}^{-1}\right)\right)$ values $^{12}$ were determined from the spectral change of 2,6diphenyl-4-(1,2,4-triphenylpyridinio)phenolate (DTP) and bis(1,3-propanediolato)vanadium(IV) (VO(acac) $)_{2}$, where $\lambda, \lambda_{\mathrm{II}}$, and $\lambda_{\mathrm{I}}$ denote the absorption maximum wavelengths $(\mathrm{nm})$ of DTP and $\mathrm{VO}(\mathrm{acac})_{2}\left(E_{\mathrm{T}}(30)\right.$ is abbreviated as $E_{\mathrm{T}}$ for simplicity). We also applied the phase separation to extraction of ion-pair complexes of tris(1,10-phenanthroline)iron(II) (Fe(phen) $)^{2+}$ ) and cationic ligands of 8-quinolinol (Hox) and 5,10,15,20tetraphenylporphyrin $\left(\mathrm{H}_{2} \mathrm{tpp}\right)$, and metal-chelates of 8quinolinol and 1-(2-pyridylazo)-2-naphthol (Hpan). A large change in the chemical properties of the solvents by the salting-out was observed for acetonitrile, 1,4dioxane, and tetrahydrofuran, but the change was small for 1-propanol and 2-propanol. Thus, acetonitrile and 1,4-dioxane were used to examine the effect of the salting-out on the extraction of metal chelates and ionpair complexes. Possible mechanisms responsible for change in $E_{\mathrm{T}}$ values and the solvent extraction using the salting-out are discussed.

\footnotetext{
† To whom correspondence should be addressed.
} 


\section{Experimental}

\section{Reagents}

The purification of 1,4-dioxane was performed as follows: solid potassium hydroxide was added to 1,4dioxane; the solution was left for 1 day and then refluxed under metal sodium; this was followed by distillation. Acetonitrile was purified by distillation in the presence of molecular sieves. All other organic solvents and chemicals were analytical reagents and were used without further purification.

\section{Procedure}

Into a stoppered graduated tube, a $5-\mathrm{cm}^{3}$ volume of aqueous sample solution was poured, then and $1.169 \mathrm{~g}$ $\left(2.00 \times 10^{-2} \mathrm{~mol}\right)$ of sodium chloride was added to the solution. The sodium chloride was dissolved sufficiently and a $5-\mathrm{cm}^{3}$ volume of organic solvent was added to the aqueous solution; then the mixed-solvent was shaken for about $1 \mathrm{~min}$. Two phases were allowed to stand for a few minutes. The volume of each of the two phases was measured, and the concentration of chloride ion and water in the separated-organic phase were determined by argentmetry and Karl Fisher titration on a Karl Fisher Moisture Titrator (MKL-200, Kyoto Electronics, Japan). Absorption spectra of metal-chelates, ion-pair complexes, and the porphyrin were recorded on a Shimadzu UV-VIS spectrophtometer 2100. The $\mathrm{pH}$ of the aqueous phase after the salting-out was measured on a Radiometer Ion 85 Ion Analyzer. All experiments were carried out at $25^{\circ} \mathrm{C}$.

\section{Results and Discussion}

\section{Phase separation of polar solvent from aqueous solutions}

Fourteen water-miscible polar solvents were examined for salting-out from $4 \mathrm{~mol} \mathrm{dm}^{-3}$ of sodium chloride. Of the water-miscible polar solvents, acetone, acetonitrile, 1,4-dioxane, tetrahydrofuran, 1-propanol, and 2-propanol were easily separated from aqueous solutions, whereas the phase separation was not observed for the following solvents: methanol, ethanol, 1-butanol, formamide, $N$-methylformamide, propylenecarbonate, $N, N$ - dimethylformamide, and $N, N$-dimethyl sulfoxide. The volumes of the separated phases and the concentrations of water and chloride in the phase-separated organic solvents are summarized in Table 1, together with donor numbers (DN) and acceptor numbers (AN) of the pure solvents. The volumes of the organic phases recovered from the salting-out were smaller than the initial volumes of the organic solvents for acetone, acetonitrile, 1,4dioxane, and tetrahydrofuran, but the volumes of 1propanol and 2-propanol were larger than their initial volumes. Propanol interacts strongly with water molecules through hydrogen-bonding and the alkyl group is hydrophobic. Thus, aqueous propanol solution is easily salted-out by the addition of sodium chloride and yields a large volume of the separated organic phase containing a lot of water. The phase-separated solvents contain water and chloride ion to a great extent and the concentration of chloride in the organic phase increases with the concentration of water in the organic phase.

Two theories have been used to explain salting-out phenomena. Long and $\mathrm{McDevit}^{8}$ have considered the salting-out as arising from electrostriction of the solvent caused by addition of electrolyte, where the Setschenow constant $\left(k_{\mathrm{s}}\right)$ has been expressed by the partial molar volumes of the electrolyte and the organic solvent and the compressibility of water. ${ }^{8-10}$ Another quantitative description has been made based on Scaled-Particle theory. ${ }^{13,14}$ The parameters used for the electrolyte in this theory are the diameters and polarizabilities of the cation and anion, and the apparent molar volume of the electrolyte at infinite dilution in water. The scaledparticle theory is useful in understanding solute-solvent interactions, but quantitative description by the theory is not possible for the relatively high concentrations used in this study. Furthermore, the theory does not give any information about change in the chemical properties of the solvents after the salting-out. Thus we measured $E_{\mathrm{T}}$ and $D_{\mathrm{II}, \mathrm{I}}$ values to elucidate the chemical properties of the phase-separated organic solvents.

\section{Donor and acceptor abilities of phase-separated solvents}

It is expected that the dissolution of sodium chloride and water into the phase-separated solvents would alter the chemical properties of the solvents. Thermodynamic quantities which represent a measure of the donor and

Table 1 Salting-out data for the phase-separation by sodium chloride ${ }^{a}$

\begin{tabular}{|c|c|c|c|c|c|c|c|}
\hline \multirow{2}{*}{ Solvent } & \multicolumn{2}{|c|}{ Volume $/ \mathrm{cm}^{3}$} & \multicolumn{2}{|c|}{ Water in organic phase } & \multirow{2}{*}{$\begin{array}{l}\text { Chloride in organic } \\
\text { phase } / 10^{-2} \mathrm{~mol} \mathrm{dm}^{-3}\end{array}$} & \multirow{2}{*}{$\begin{array}{l}\text { Donor }^{b} \\
\text { number }\end{array}$} & \multirow{2}{*}{$\begin{array}{l}\text { Acceptor } \\
\text { number }\end{array}$} \\
\hline & Organic phase & Aqueous phase & $\%(w / w)$ & $x$ (mole fraction) & & & \\
\hline Acetone & 3.11 & 6.99 & 17.3 & 0.390 & 9.62 & 17.0 & 12.5 \\
\hline Acetonitril & 4.17 & 6.11 & 10.3 & 0.208 & 2.49 & 14.1 & - \\
\hline 1,4-Dioxane & 2.04 & 8.16 & 9.55 & 0.340 & 2.06 & 14.8 & 10.8 \\
\hline Tetrahydrofuran & 4.66 & 5.65 & 5.99 & 0.203 & 0.162 & 20.0 & 8.0 \\
\hline 1-Propanol & 5.27 & 4.97 & 18.4 & 0.430 & 16.4 & - & - \\
\hline 2-Propanol & 5.21 & 4.95 & 24.2 & 0.516 & 28.2 & - & 33.5 \\
\hline
\end{tabular}

a. Five cubic centimeters of each solvent and of water were taken initially and $1.169 \mathrm{~g}\left(2.00 \times 10^{-2} \mathrm{~mol}\right)$ of sodium chloride was added. b. Donor number and acceptor number of water are 18.0 and 54.8 , respectively (ref. 15). 


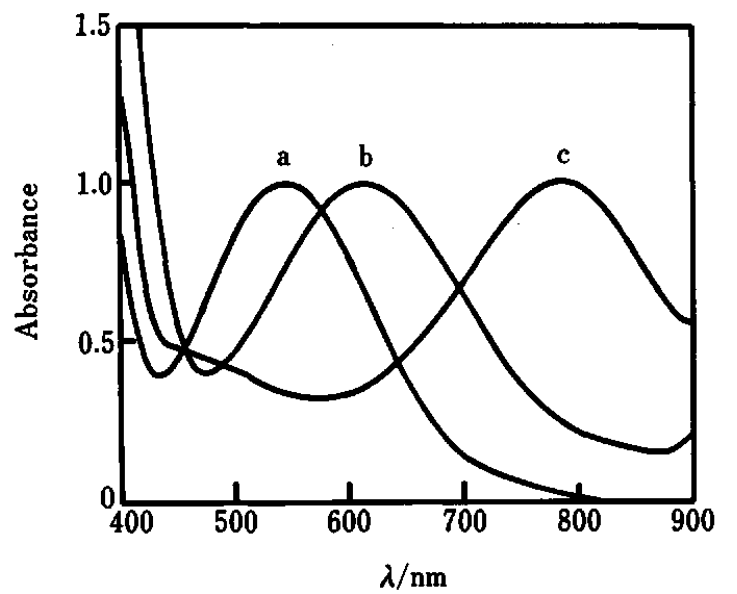

Fig. 1 Typical spectral change of 2,6-diphenyl-4-(2,4,6triphenylpyridinio)phenolate (DTP) in $1: 1(\mathrm{v} / \mathrm{v})$ waterdioxane mixed solvent (a), 1,4-dioxane after salting-out (b), and pure 1,4-dioxane (c).

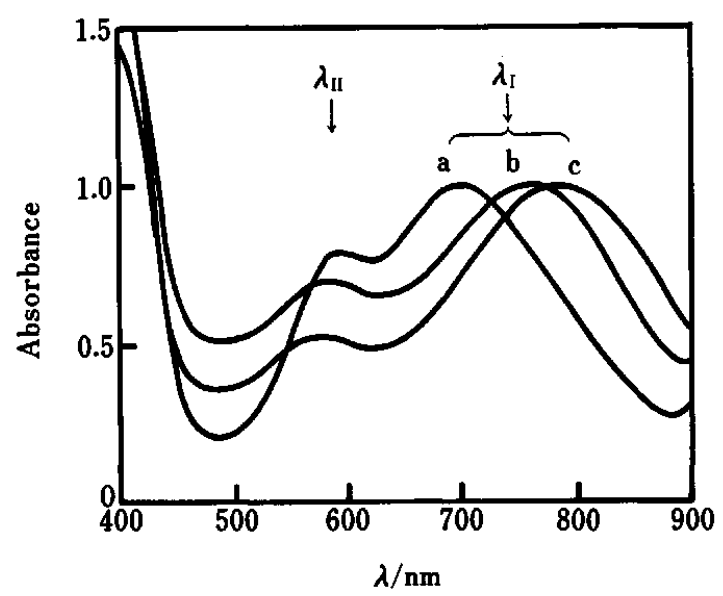

Fig. 2 The d-d spectral change of $\mathrm{VO}(\mathrm{acac})_{2}$ in pure acetonitrile (a), acetonitrile after salting-out (b), and 1:1 $(v / v)$ water-acetonitrile mixed solvent (c). Two absorption maxima at lower and higher wavelengths correspond to $\lambda_{\mathrm{II}}$ and $\lambda_{1}$, respectively.

the acceptor properties of solvent have been presented by Gutmann and Mayer as donor number and acceptor number. ${ }^{15}$ These parameters have succeeded in explaining a lot of chemical reactions in nonaqueous solvents. Furthermore, the electronic transitions of various indicator molecules strongly depend on solvent, so the transition energies in different solvents have been used as an empirical measure of solvent polarity. One of these parameters is the $E_{\mathrm{T}}$ value based on the energy transition of the pyridinium phenol betain. ${ }^{11}$ Absorption spectra of DTP are given in Fig. 1 for 1,4-dioxane. The $E_{\mathrm{T}}$ values have been linearly correlated to the acceptor numbers defined by Mayer. ${ }^{15}$ The other parameter is $D_{\mathrm{II}, \mathrm{I}}$ value calculated by spectral change of $\mathrm{VO}(\mathrm{acac})_{2}$. When this complex is dissolved in donor solvent, the $d-d$ absorption of this chelate appears in the red part of the visible spectrum composed of two bands, $\lambda_{\mathrm{I}}$ and $\lambda_{\mathrm{II}}$ in non-polar solvent (Fig. 2). With an increase of donor number of the solvent, the $\lambda_{1}$ is notably shifted to the red, while the $\lambda_{\text {II }}$ is shifted a little to the blue, so that the difference in their frequency values $\left(D_{\mathrm{II}, \mathrm{l}}\right)$ increases with the donor number of the aprotic solvent used. However, a protic solvent which can form hydrogen bonds generally yields much higher $D_{\mathrm{III}}$ values than those expected from their DN alone. ${ }^{16}$ Such effects have been ascribed to the solvation of oxygen atom of the $\mathrm{V}=\mathrm{O}$ group by solvent molecules which behave as acceptors. It is easy to see that such a solvation weakens the $\mathrm{V}=\mathrm{O}$ bond, making it more polar (i.e. like $\mathrm{V}^{+}-\mathrm{O}^{-}$). This, in turn, favors a solvation by donor solvent molecules from behind the chelate plane. Figure 3 and Table 2 show the $E_{\mathrm{T}}$ and $\mathrm{D}_{\mathrm{II}, 1}$ values

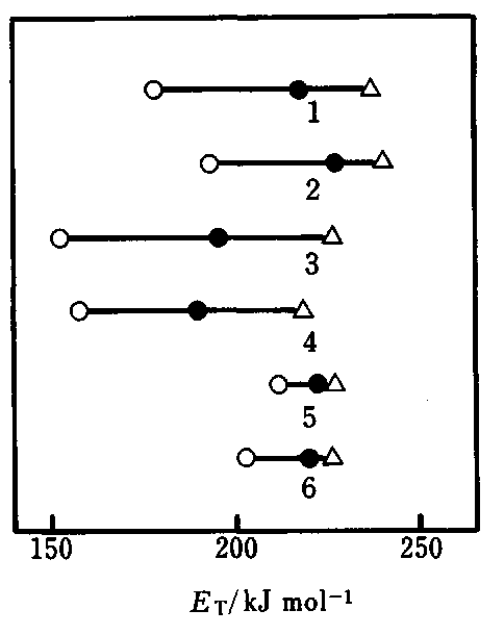

Fig. $3 E_{\mathrm{T}}$ values of water-miscible pure solvents $(\mathrm{O})$, organic phase after the salting-out (O), and 1:1 mixed-aqueous solutions $(\Delta)$. Solvents are acetone $(1)$, acetonitrile $(2), 1,4-$ dioxane (3), tetrahydrofuran (4), 1-propanol (5), and 2propanol (6).

Table $2 D_{\mathrm{II}, \mathrm{l}}$ values of water-miscible pure solvents, the organic solvents after the salting-out, and mixed solvents at $25^{\circ} \mathrm{C}$

\begin{tabular}{lccc}
\hline \multirow{2}{*}{ Solvent $^{\mathrm{a}}$} & \multicolumn{3}{c}{$D_{\mathrm{II}, \mathrm{I}} / \mathrm{kJ} \mathrm{mol}^{-1}$} \\
\cline { 2 - 4 } & Pure solvent & Salting-out $^{\mathrm{b}}$ & Mixed-solvent $^{\mathrm{c}}$ \\
\hline AC & 31.6 & 45.8 & 55.3 \\
AN & 30.2 & 48.0 & 55.0 \\
Dioxane & 38.4 & 42.8 & 53.8 \\
THF & 43.4 & 41.8 & 51.8 \\
1-PrOH & 50.4 & 54.0 & 56.4 \\
2-PrOH & 49.1 & 52.9 & 57.1 \\
\hline
\end{tabular}

a. Solvents are abbreviated as follows: AC, acetone; AN, acetonitrile; THF, tetrahydrofuran; 1-PrOH, 1-propanol; and 2-PrOH, 2-propanol.

b. Solvents of the organic phase after salting-out.

c. Solvents before addition of sodium chloride. 


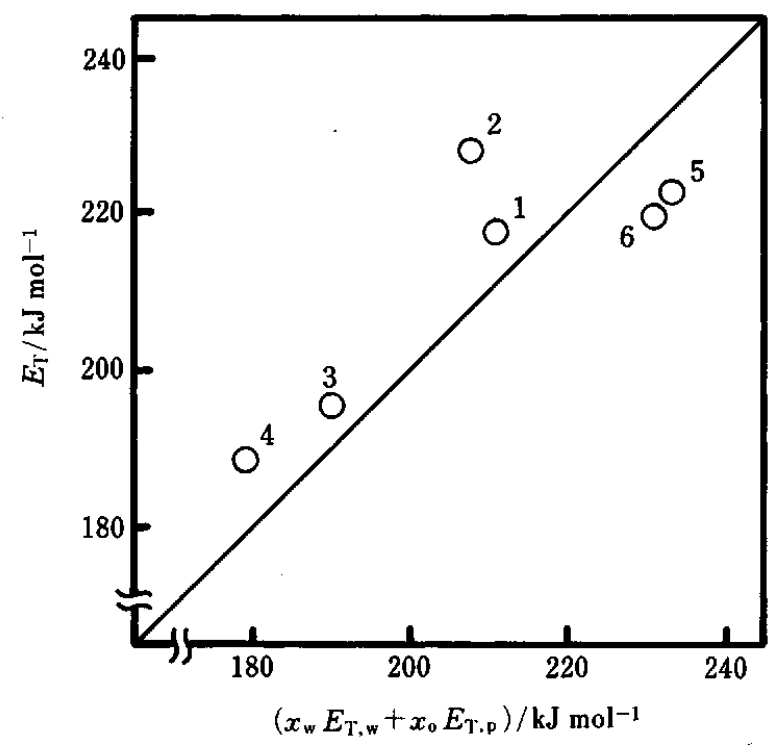

Fig. 4 Plot of observed $E_{\mathrm{T} . \mathrm{s}}$ of the organic phase after the salting-out against calculated value from $x_{\mathrm{w}} E_{\mathrm{T}, \mathrm{w}}+x_{\mathrm{o}} E_{\mathrm{T}, \mathrm{p}}$. The solid line shows an ideal mixing of water and organic solvents in the phase-separated solvents. Refer to Fig. 3 for explanation of numerical figures.

measured in the pure solvents, the phase-separated organic solvents, and the mixed solvents; here $E_{\mathrm{T}}$ values of pure solvents are good agreement with the reported values. ${ }^{11}$ All these data suggest that the donor and acceptor properties of the phase-separated solvents (except propanol) increase by the salting-out compared to the pure solvents and are smaller than those of the mixed solvent before the salting-out. For tetrahydrofuran, the $D_{\mathrm{III}, \mathrm{I}}$ value of the organic phase is comparable to that of pure tetrahydrofuran. One reason is that the donor ability of tetrahydrofuran is not seriously affected by the salting-out due to comparable donor numbers of tetrahydrofuran $(\mathrm{DN}=20)$ and water $(\mathrm{DN}=18)$. The change in $E_{\mathrm{T}}$ values by the salting-out is large for acetone, acetonitrile, 1,4-dioxane, and tetrahydrofuran, but is small for 1-propanol and 2-propanol (Fig. 3). The main factor for the change in $E_{\mathrm{T}}$ value is the increased water molecules in the phase-separated solvent: acceptability of the phase-separated solvents is altered by incorporation of water having a large acceptor number $(\mathrm{AN}=54.8)$. If the phase-separated solvent is an ideal mixture of the component without any interaction, the $E_{\mathrm{T}}$ value of the phase-separated organic solvent, $E_{\mathrm{T}, s}$, is given by the following equation:

$$
E_{\mathrm{T}, \mathrm{s}}=x_{\mathrm{w}} E_{\mathrm{T}, \mathrm{w}}+x_{\mathrm{o}} E_{\mathrm{T}, \mathrm{p}}
$$

where $E_{\mathrm{T}, \mathrm{w}}\left(264 \mathrm{~kJ} \mathrm{~mol}^{-1}\right)$ and $E_{\mathrm{T}, \mathrm{p}}$ are $E_{\mathrm{T}}$ values of pure water and pure organic solvent, respectively, and $x_{\mathrm{w}}$ and $x_{0}$ refer to mole fraction of water and organic solvent in the phase-separated organic solvent. In Fig. 4, the observed $E_{\mathrm{T}}$ value is plotted against the right-hand side of Eq. (1). The solid line corresponds to ideal mixing of the phase-separated solution. The observed $E_{\mathrm{T}}$ values

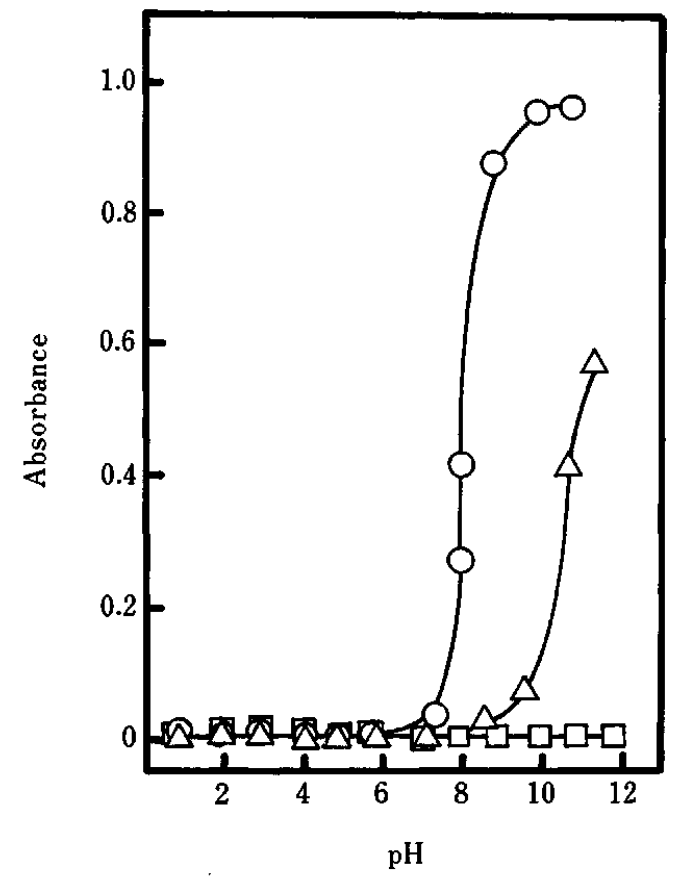

Fig. 5 Extraction of zinc(II) $(O)$, cadmium(II) $(\triangle)$ and lead(II) ( $\square$ ) with 1-(2-pyridylazo)-2-naphthol into 1,4dioxane by the salting-out. The initial concentration of the metal ion is $8.0 \times 10^{-6} \mathrm{~mol} \mathrm{dm}^{-3}$ in aqueous phase.

of acetonitrile, 1-propanol, and 2-propanol deviate from the calculated line: the values are larger for acetonitrile and smaller for propanol than the calculated ones. Since water has the largest $E_{\mathrm{T}}$ among the solvents studied, we have to consider the effect of water molecules on the $E_{\mathrm{T}, \mathrm{s}}$ value in the phase-separated solution. Propanol forms a hydrogen-bond structure in its solvent and interacts with water molecules through hydrogenbonding. Hence it is expected that the change in chemical property of propanol by the salting-out will be small, as shown in Fig. 3. Furthermore, solvation of DTP by water molecules may be decreased by hydrogenbonding of propanol to water molecules. Thus the change in chemical properties of propanol will become smaller than the calculated value. On the other hand, acetonitrile is almost a monomer in its solvent and interacts with water molecules more weakly than propanol. Thus the change in chemical property of acetonitrile was largely altered by the salting-out. The acidity of water in the phase-separated acetonitrile increases compared to that in pure water, due to the increased number of water molecules capable of hydrogen-bonding in acetonitrile.

\section{Extraction of metal chelates}

The solvent extraction with 1,4-dioxane salted-out by sodium chloride was studied using 1-(2-pyridylazo)-2naphthol and 8-quinolinol. A 5- $\mathrm{cm}^{3}$ volume of metal nitrate solution $\left(\mathrm{Zn}^{2+}, \mathrm{Cd}^{2+}\right.$, and $\mathrm{Pb}^{2+} ; 8.00 \times 10^{-6} \mathrm{~mol}$ $\mathrm{dm}^{-3}$ ) was taken into a test tube with a stopper. Sodium chloride of $1.169 \mathrm{~g}\left(2.00 \times 10^{-2} \mathrm{~mol}\right)$ was added to the 


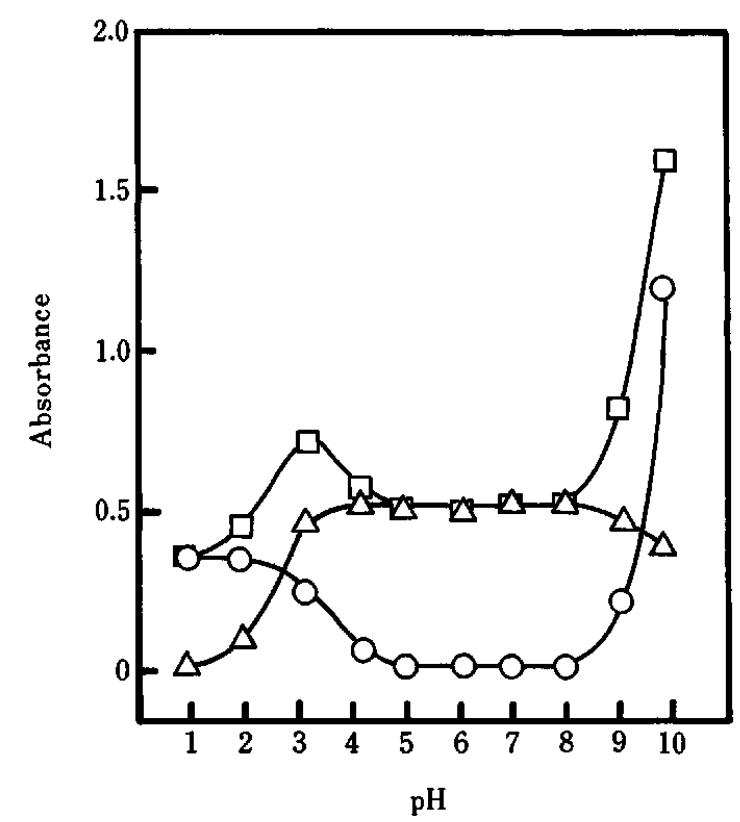

Fig. 6 Extraction of copper(II) ion with 8-quinolinol into 1,4dioxane by the salting-out. Absorbances at $420 \mathrm{~nm}$ are plotted against $\mathrm{pH}$ in the absence $(O)$ and presence $(\square)$ of copper(II) $\left(2 \times 10^{-6} \mathrm{~mol} \mathrm{dm}^{-3}\right)$. Absorbance against the reagent blank $(\triangle)$.

aqueous solution, followed by the addition of a $5 \mathrm{~cm}^{3}$ of 1,4-dioxane solution containing Hpan $\left(2.00 \times 10^{-5} \mathrm{~mol}\right.$ $\mathrm{dm}^{-3}$ ). The sample solution was shaken for $1 \mathrm{~min}$ and then the absorbance of the 1,4-dioxane phase was measured at $553 \mathrm{~nm}$. Results are summarized in Fig. 5. The $\mathrm{pH}$ values of the aqueous solutions were adjusted by hydrochloric acid, acetate buffer, piperazine-1,4-bis(2ethanesulfonic acid) (PIPES buffer), ammonia buffer, borate buffer, and sodium hydroxide. The data in this experiment confirm that the equilibrium between the two phases is established rapidly and that zinc(II) is completely extracted into the 1,4-dioxane salted-out at pH larger than 10 . Lead(II) was not extracted into the 1,4-dioxane phase over a wide $\mathrm{pH}$ range from 1 to 12 . Cadmium(II) was extracted partly at pH higher than 10 . The results suggest a selective determination of zinc(II) in lead(II).

Solvent extraction of copper(II)-8-quinolinol complex into 1,4-dioxane phase was also examined. The extraction method and $\mathrm{pH}$ adjustment were the same as those used for extraction of zinc(II), cadmium(II), and lead(II) using Hpan. The initial concentrations of copper(II) in aqueous solution and the 8-quinolinol in 1,4-dioxane were $4.00 \times 10^{-5} \mathrm{~mol} \mathrm{dm}^{-3}$ and $2.00 \times 10^{-2} \mathrm{~mol}$ $\mathrm{dm}^{-3}$, respectively. The absorbance of the separated organic phase was measured at $420 \mathrm{~nm}$. The results are given in Fig. 6. The absorbance is constant over a $\mathrm{pH}$ range between 5 to 8 , but increases at both lower and higher pHs. 8-Quinolinol was extracted into the 1,4dioxane phase even at acidic or alkaline solution. The ion-pairs of 8-quinolinol with chloride $\left(\left[\mathrm{H}_{2} \mathrm{Ox}^{+} \mathrm{Cl}^{-}\right]\right)$and sodium ion $\left(\left[\mathrm{Na}^{+} \mathrm{Ox}^{-}\right]\right)$were extracted at acidic and alkaline solutions, respectively. This is a characteristic phenomenon of the present solvent extraction method into the separated organic phase by the salting-out. The extraction of the acidic form was also observed for 5,10,15,20-tetraphenylporphyrin, where $\left[\mathrm{H}_{4} \mathrm{tpp}^{2+} \mathrm{Cl}^{-}\right]$ was extracted. The phase-separated 1,4-dioxane contains water and chloride ion, and has high donor and acceptor abilities compared to pure 1,4-dioxane. Thus, the ion-pair complex is easily extracted into the phaseseparated organic solvent by the salting-out.

\section{Distribution of the ion-pair complex of tris(1,10-phenan- throline)iron(II)}

In the previous section we described how the cationic or anionic chemical species like porphyrin $\left(\mathrm{H}_{4} \mathrm{tpp}^{2+}\right)$ and 8-quinolinol $\left(\mathrm{H}_{2} \mathrm{Ox}^{+}\right.$or $\left.\mathrm{ox}^{-}\right)$were extracted into the phase-separated 1,4-dioxane as their ion-pairs. We examined the extraction of tris(1,10-phenanthroline)iron(II) complex $\left(\mathrm{Fe}(\mathrm{phen})_{3}{ }^{2+}\right)$ into six solvents (acetone, acetonitrile, 1,4-dioxane, tetrahydrofuran, 1-propanol, and 2-propanol) separated by the salting-out in order to confirm the application to the solvent extraction of ionpair. One cubic centimeters volume of an aqueous solution of $\mathrm{Fe}$ (phen $)_{3}{ }^{2+}\left(5.00 \times 10^{-4} \mathrm{~mol} \mathrm{dm}^{-3}\right)$ was taken in a test tube with a stopper, followed by the addition of $1 \mathrm{~cm}^{3}$ of acetate buffer $\left(1.0 \times 10^{-1} \mathrm{~mol} \mathrm{dm}{ }^{-3} ; \mathrm{pH} 5\right), 3 \mathrm{~cm}^{3}$ of pure water, $1.169 \mathrm{~g}$ of sodium chloride, and $5 \mathrm{~cm}^{3}$ organic solvent. After vigorous shaking for $1 \mathrm{~min}$, we measured the absorbance at $512 \mathrm{~nm}$, which is the absorption maximum of $\mathrm{Fe}^{\mathrm{II}}(\text { phen })_{3}{ }^{2+}$. The percent extractions $(\%)$ of $\mathrm{Fe}(\text { phen })_{3}{ }^{2+}$ into water-miscible solvents after the salting-out were as follows: 4.4 (acetone), 84.4 (acetonitrile), 0 (1,4-dioxane), 0.5 (tetrahydrofuran), 83.4 (1-propanol), 45.1 (2-propanol). The iron(II) complex was extracted into acetonitrile, 1-propanol, and 2-propanol. For 1,4-dioxane, the ion-pair was not extracted by salting-out due to a large solubility of 1,4-dioxane in water phase. Furthermore, potassium permanganate was extracted into acetonitrile from an alkaline solution. The ion-pair extractions of $\mathrm{Fe}(\mathrm{phen})_{3}{ }^{2+}$ with anions like halides, thiocyanate, and perchlorate were studied using chloroform by Yamamoto. ${ }^{17}$ The $\mathrm{Fe}$ (phen) ${ }_{3}{ }^{2+}$-chloride complex was extracted only to a few percents into chloroform under the present experimental conditions. The equilibrium and chemical species in the extraction of $\mathrm{Fe}$ (phen) $)^{2+}$ with anions into acetonitrile are now being studied and will be reported later.

In summary, the change in $E_{\mathrm{T}}$ and $D_{\mathrm{II}, \mathrm{I}}$ values after salting-out indicates that some chemical properties of the phase-separated solvents are varied by the salting-out. Especially, acceptability increases due to the dissolution of water molecules having large acceptor numbers into the organic phases. The dissolution of sodium chloride also enhances the acidity of the solvents because of the increased acidity of solvated water molecule to sodium ion. ${ }^{18,19}$ The altered chemical properties increase the feasibility of the extraction of ion-pairs compared to other organic solvents like chloroform, 1,2-dichloro- 
ethane, and nitrobenzene. An other feature of the salting-out is that chemical reaction occurs in a homogeneous solvent before separation, so this would be convenient for the extraction of metal-chelates of inert metal ions. Furthermore, the present method will be used to change the chemical property of the acetonitrilewater mixed solvent, which is used widely as an eluting solvent in HPLC.

The present work was supported by a Grant-in-Aid for Scientific Research from the Ministry of Education, Science and Culture of Japan (05453071).

\section{References}

1. C. E. Matkovich and G. D. Christian, Anal. Chem., 45, 1915 (1973).

2. B. J. Mueller and R. J. Lovett, Anal. Chem., 59, 1405 (1987).

3. D. C. Leggett, T. F. Jenkins and P. H. Miyares, Anal. Chem., 62, 1355 (1990).

4. T. Fujinaga and Y. Nagaosa, Bull. Chem. Soc. Jpn., 53, 416 (1980).

5. H. Kawamoto and H. Akaiwa, Chem. Lett., 1973, 259.

6. W. J. Horvath and C. W. Huie, Talanta, 39, 487 (1992).
7. S. Igarashi and T. Yotsuyanagi, Mikrochim. Acta, 106, 37 (1992).

8. F. A. Long and W. F. McDevit, Chem. Rev., 51, 119 (1952).

9. M. Fromon and C. Treiner, J. Chem. Soc., Faraday Trans. 1, 75, 1837 (1979).

10. C. V. Krishnan and H. L. Friedman, J. Solution Chem., 3, 727 (1974).

11. C. Reichardt, "Solvents and Solvent Effects in Organic Chemistry", VCH, Weinheim, 1988.

12. K. Sone and Y. Fukuda, "Inorganic Thermochromism", Springer, New York, 1987.

13. R. Aveyard and R. Heselden, J. Chem. Soc., Faraday Trans. 1, 71, 312 (1975).

14. R. A. Pierotti, Chem. Rev., 76, 717 (1976).

15. V. Gutmann, "The Donor-Acceptor Approach to Molecular Interactions", Plenum Press, New York, 1978.

16. V. Gutmann, "Coordination Chemistry in Non-Aqueous Solutions", p. 22, Springer, Wien, 1968.

17. Y. Yamamoto, Bunseki Kagaku, 21, 418 (1972).

18. E. Iwamoto, J. Nishimoto, T. Yokoyama, K. Yamamoto and T. Kumamaru, J. Chem. Soc., Faraday Trans., 87, 1537 (1991).

19. J. Nishimoto, A. Hironaka, E. Iwamoto and T. Kumamaru, Bull. Chem. Soc. Jpn., 66, 1669 (1993).

(Received January 17, 1994) (Accepted March 25, 1994) 